\title{
Effects of Tumour Necrosis Factor- $\alpha$ on Human Sperm Motility and Apoptosis
}

\author{
Anna Perdichizzi • Ferdinando Nicoletti • \\ Sandro La Vignera $\cdot$ Nunziata Barone . \\ Rosario D'Agata • Enzo Vicari • Aldo E. Calogero
}

Published online: 18 September 2007

(C) Springer Science + Business Media, LLC 2007

The correct spelling of the last author's full name is Aldo

E. Calogero.

The online version of the original article can be found at http://dx.doi. org/10.1007/s10875-007-9071-5.

A. Perdichizzi $\cdot$ S. La Vignera $\cdot$ N. Barone $\cdot$ R. D'Agata $\cdot$

E. Vicari $\cdot$ A. E. Calogero $(\bowtie)$

Section of Endocrinology, Andrology and Internal Medicine, and Master in Andrological and Human Reproduction Sciences, University of Catania,

Catania, Italy

e-mail: acaloger@unict.it

F. Nicoletti

Department of Biomedical Sciences, University of Catania, Catania, Italy

\section{A. E. Calogero}

Sezione di Endocrinologia, Andrologia e Medicina Interna,

Dipartimento di Scienze Biomediche, Università di Catania,

Ospedale Garibaldi Centro, Piazza S. Maria di Gesù,

95123 Catania, Italy 